\title{
A SYSTEMATIC REVIEW OF CYBERBULLYING IN CHILDREN AND KiVa PROGRAM FOR TRAUMA HEALING
}

\author{
Aris Widiyanto \\ School of Health Sciences Mamba'ul 'Ulum, Surakarta
}

\begin{abstract}
Background: Bullying involves behaviors such as verbal abuse, ridicule, insults and threats, as well as physical aggression, such as hitting, kicking, punching, and damaging other people's things. Cyberbullying involves the use of electronic media with the aim of causing damage, humiliation, suffering, fear and despair for individuals who are targets of aggression. Criteria for "cyberbullying": attacks are intentional, occur repeatedly, and cause psychological distress. The impact of cyberbullying is not only on daily lives but may continue to adulthood. KiVa is a research-based anti-bullying program that has been developed in the University of Turku, Finland, with funding from the Ministry of Education and Culture. The effectiveness of KiVa has been shown in a large randomized controlled trial. This study aimed to describe the emerging health problems and evidence-based intervention programs that support trauma healing through KiVa program.

Subjects and Method: A systematic review was conducted by searching the following databases: PubMed, SAGE Journals, and Virtual Health Library, from 2010 to 2018. The keywords for this review included cyberbullying AND children, cyberbullying AND mental health AND Children, cyberbullying in children AND intervention. The inclusion criteria were systematic review, clinical review, cohort study, cross-sectional study, clinical study and guideline. After review process 19 articles and 1 RCT were included.

Results: Internationally, the impact of cyberbullying on children has been linked to poor mental health including overall psychological health, low self-esteem, depression, anxiety, and violent behavior. Another study showed that bully victims had the highest risk of selfinjury $(\mathrm{PR}=4.7 ; 95 \% \mathrm{CI}=3.26$ to 6.83$)$, suicidal ideation $(\mathrm{PR}=4.3 ; 95 \% \mathrm{CI}=2.83$ to 6.49$)$, suicide plan ( $P R=4.1 ; 95 \% \mathrm{CI}=2.54$ to 6.58$)$ and effort $(\mathrm{PR}=2.7 ; 95 \% \mathrm{CI}=1.39$ to 5.13$)$. $\mathrm{KiVa}$ is a school-based anti-bullying program from Finland involving teachers, students and parents. The KiVa principle is the prevention of bullying by cultivating character in students by forming group norms. The forms vary, can be videos, online games, surveys, posters, and guidebooks for parents. Children are taught a sense of responsibility and empathy. Previous RCT studies consisting of 2,042 students in grades 4 and 6 showed that KiVa reduced intimidation, pro-intimidation and victimization. And increasing attitudes and empathy for victims. Overall, the findings provide evidence of the effectiveness of the KiVa Program.

Conclusion: Cyberbullying is associated with emotional stress and even suicide attempts. Parents, health workers, and educators must be aware of the long-term risks so that prevention and treatment programs such as KiVa should be considered for application in Indonesia.
\end{abstract}

Keywords: cyberbullying, children, mental health

\section{Correspondence:}

Aris Widiyanto. School of Health Science Mamba'ul 'Ulum, Surakarta, Jl. Ring Road Utara, Tawangsari, Mojosongo, Jebres, Surakarta, Central Java.

Email: widiyantoaris99@gmail.com: 081329209095.

The 5th International Conference on Public Health

Best Western Premier Hotel, Solo, Indonesia, February 13-14, $2019 \mid 158$

https://doi.org/10.26911/theicph.2019.02.03 